\title{
Psychiatric risk assessment from the Clinician's perspective: Lessons for the future
}

Alex S. Cohen ${ }^{1 *} \cdot$ Taylor Fedechko ${ }^{1}$ Elana K. Schwartz ${ }^{1} \cdot$ Thanh Le $^{1} \cdot$ Peter W. Foltz $^{2} \cdot$ Jared Bernstein $^{3}$. Jian Cheng ${ }^{3} \cdot$ Elizabeth Rosenfeld ${ }^{3} \cdot$ Brita Elvevåg ${ }^{4,5}$

1 Department of Psychology, Louisiana State University, 236 Audubon Hall, Baton Rouge, LA 70803, USA

2 Department of Psychology, University of Colorado, Boulder, USA

3 Analytic Measures Inc, Palo Alto, CA, USA

4 Department of Clinical Medicine, University of Troms $\varnothing$ - The Arctic University of Norway, Troms $\varnothing$, Norway

5 The Norwegian Centre for eHealth Research, University Hospital of North Norway, Troms $\varnothing$, Norway

*Correspondence to: Alex S. Cohen _ Email: acohen@1su.edu

\section{Submitted to: Community Mental Health Journal}

Previous Presentation: The data presented in this paper have not been previously published or publically presented.

Word Count: 2721

Acknowledgements: This project was funded by Grant 231395 from the Research Council of Norway awarded to Brita Elvevåg. 


\begin{abstract}
Accurate prediction of risk-states in Serious Mental Illnesses (SMIs) is critical for reducing their massive societal burden. Risk-state assessments are notably inaccurate. Recent innovations, including widely available and inexpensive mobile technologies for ambulatory "biobehavioral" data, can reshape risk assessment. To help understand and accelerate clinician involvement, we surveyed 90 multi-disciplinary clinicians serving SMI populations in various settings to evaluate how risk assessment is conducted and can improve. Clinicians reported considerable variability in conducting risk assessment, and few clinicians explicated their procedures beyond tying it to broader mental status examinations or interviews. Very few clinicians endorsed using currently-available standardized risk measures, and most reported low confidence in their utility. Clinicians also reported spending approximately half the time conducting individual risk assessments than optimally needed. When asked about improvement, virtually no clinicians acknowledged biobehavioral, objective technologies, or ambulatory recording. Overall, clinicians seemed unaware of meaningful ways to improve risk assessment.
\end{abstract}

Keywords: Risk assessment, serious mental illness, technology, machine learning, objective 


\section{The state of risk assessment for Serious Mental Illness}

Serious mental illnesses (SMIs) have a massive impact on society (Insel, 2008; Kessler et al., 2009; Stuart \& Weinrich, 1998). Much of this impact stems from treating psychiatric emergencies involving unfortunate events such as suicidality, self-harm, homicidality/harm to others, functional decompensation, relapse from substance use, and medication side-effects (Stuart \& Weinrich, 1998; Wu et al., 2005). Thus, accurate and efficient assessment of these various psychiatric "risk states" are critical for reducing the burden of psychiatric disease. At present, a host of “empirically-supported" psychiatric risk assessments exist (Wand, 2012). While these assessments vary in scope and approach, current evidence raises serious questions about their accuracy for predicting psychiatric events at the individual level for suicidality (Bernert, Hom, \& Roberts, 2014; Chan et al., 2016; H. D. Nelson et al., 2017), homicidality (Campbell, French, \& Gendreau, 2009; Yang, Wong, \& Coid, 2010), decompensation (Joseph et al., 2017; O’Hagan, Cornelius, Young, \& Taylor, 2017), treatment compliance (Rubin, Dolev, \& Zilcha-Mano, 2016; Velligan et al., 2009), and psychosis (Schmidt et al., 2017). Consider, for example, meta-analysis suggesting that clinicians are no better than chance for predicting suicide (e.g., Grove et al., 2000), and that the "validated" measures for predicting suicide confer only a five to ten percent advantage over this (e.g., Grove et al., 2000, Chan et al., 2016). Similarly, Large and colleagues (Large et al., 2019) reported that current risk assessment tools are inaccurate for predicting suicide behavior even in "high" risk patients; with about half of all suicides occurring in low-risk groups and $95 \%$ of high-risk patients not attempting suicide. In short, our ability to accurately predict behavior in an individual over a relatively brief temporal epoch with acceptably low false positive rates is currently unacceptable.

To complement traditional risk assessment approaches, there have been efforts to advance risk prediction using objective data analysis such as using genetic, neurobiological, physiological, and ambulatory tracking data (Cohen \& Elvevåg, 2014; Nelson, McGorry, Wichers, Wigman, \& Hartmann, 2017; Seidman et al., 2016; Vassos et al., 2017). Although these "nontraditional" efforts have existed for decades, three major advances are helping reshape how risk assessments are conducted. The first major advance is that "biobehavioral" measures, evaluating specific channels of objectively-defined behavior (e.g., electro-encephalography (EEG), eye-tracking, facial and speech analysis) have become relatively inexpensive. Second, many of these technologies yield continuous data streams that can be collected unobtrusively while a patient navigates their daily routine - thus extending assessment well beyond the confines of the traditional clinical setting (Ben-Zeev et al., 2012; Ben-Zeev, Davis, Kaiser, Krzsos, 
\& Drake, 2013). These include a variety of passive monitoring, psychophysiology, natural language processing, social media, and self-report recording approaches. Third, within the last decade methodological and statistical procedures have become more available for analyzing these "big data" streams (Torous \& Baker, 2016). Collectively, these advances hold the potential to provide low-cost and time-efficient assessment procedures that are translatable to a wide array of risk-states. To date, a number of projects have been proposed and evaluated to improve risk assessment of suicide/self-harm (Bridge, Horowitz, \& Campo, 2017; Gaynes et al., 2004), homicide/harm-to-others (Vitacco, Tabernik, Zavodny, Bailey, \& Waggoner, 2016), psychosis onset and decompensation (Ben-Zeev et al., 2013; Cannon et al., 2016; Carrión et al., 2016), cognitive decline (Harrison et al., 2017) and mania (Hafeman et al., 2017). The potential of these efforts has garnered support from major organizations (Boudreaux \& Horowitz, 2014; Cannon et al., 2008a, 2016; Heeringa et al., 2013; Hoffmire et al., 2016a; Insel, 2008; Schoenbaum et al., 2014a). With respect to suicide, machine-learning based algorithms using medical record (e.g., Walsh, 2017) and various biobehavioral technologies (e.g., Pestian et al., 2017) have been developed with impressive accuracy rates (e.g., exceeding 85\%). These advances have, in some cases, been clinically implemented (e.g., the STARRS program; Kessler et al., 2015). While advances in psychiatric risk prediction are still in their infancy, their promise for a broad range of applications is quite high - particularly given they can potentially integrate genetic, neurodevelopmental, family history, social media and varying biobehavioral data streams together.

As yet, it is unclear whether these nontraditional approaches, which are not primarily based on clinical interview and clinician judgement, have been acknowledged and received by relevant stakeholders, in particular, clinicians whose practice involves various types of risk assessment (see Cohen et al., 2019 and Holmlund et al., 2019 for additional discussion). As noted by the American Medical Informatics Association, it often takes over a decade for innovation to be implemented by practitioners in health-related fields, and this implementation tends to occur only in pockets (Beal, 2012; Kessler \& Glasgow, 2011). To address this, many have advocated that stakeholders need to be involved meaningfully and continuously from the outset of the innovation process (Peek et al., 2014). The potential pitfalls of not involving these stakeholders from inception include perceived lack of relevance as well as "laboratory" solutions that may not be suited for real-world application (Rothwell, 2005). The purpose of this paper is to survey a multidisciplinary network of clinicians about current and future risk assessment. 
This information could prove vital for developing a "next generation" of risk assessment procedures and for facilitating participation of practicing clinicians in this process. We aimed to answer four questions:

1. What types of risk are clinicians concerned about in SMI?

2. How is risk currently assessed?

3. How often, and for how long, is risk assessment conducted?

4. How can risk assessment be improved, and what role can technology play in this?

The current study was approved by the Institutional Review Board of the university of the study's lead investigator. We declare no conflict of interest. All authors certify their responsibility for this manuscript.

\section{Survey Methods:}

Invitations to participate in the present survey were sent to clinicians providing services to individuals with SMI. These clinicians include representatives from psychiatric, psychological, counseling, social work, and nursing disciplines within the state of Louisiana via professional listservs associated with these disciplines. The survey was anonymous and approved by relevant institutional research boards. Questions in the survey tapped information regarding risk assessment in SMI using a mix of multiple-choice, Likert-style ratings, and open-ended text responses. Approximately 90 clinicians began the survey and 70 completed it. Average completion time for the latter group was 36 minutes (standard deviation $[\mathrm{SD}]=3.11$ minutes). The mean age of clinicians was 45.36 years ( $\mathrm{SD}=14.59$; range 21 to 73). Information regarding the employment settings and training is provided in Table 1.

[Insert Table 1 about here]

\section{What types of risk are clinicians concerned about in SMI?}

Clinicians were presented with seven different types of risk and asked whether these reflected primary concerns for them in their practice. Nearly all indicated that risk of harming self $(88 \%)$, treatment noncompliance (77\%), and psychosis (74\%) were primary concerns in their practice. Risk of harming others (67\%) and decompensation (65\%) were also listed as common primary concerns. Medication side effects were endorsed by about half of clinicians (52\%) and risk of litigation was a primary concern for nearly one-quarter of the sample 
(22\%). These findings are consistent with extant literature in that harm to self and others is a pervasive concern in treatment of SMI patients. The relatively low endorsement of litigation as a primary concern was surprising given other studies (e.g., 75\% of psychiatrists expressed concern; Brodsky, 1988; Kennedy \& Gill, 1997; Passmore \& Leung, 2002; Wilbert \& Fulero, 1988).

\section{How is risk currently assessed?}

Clinicians were asked about risk assessment procedures they employed for the various risk types they indicated in the prior section. First, they indicated what "format" best typified their assessment procedures (i.e. formal and informal mental status exams, structured and unstructured clinical interviews, and standardized clinical measures). Following this, they rated their confidence in the aforementioned formats. Finally, they described the assessment procedure they used via text responses. Table 2 contains these data. For all types of risk, mental status exams (i.e. formal and informal) and structured clinical interviews were endorsed as the most common formats used, collectively accounting for over $80 \%$ of responses. Conversely, unstructured clinical interviews and standardized clinical measures were not frequently used. Both structured and unstructured clinical interviews, but not mental status exams, engendered the greatest confidence for clinicians, with the former accounting for almost two thirds of responses. Standardized clinical measures were not often selected, with an average endorsement of less than 5\%. When clinicians were asked to describe the assessment procedures they used, only eight clinicians responded to this and only four of these responses involved measures or procedures with published psychometric data. The others were nonspecific (e.g., "we refer to outside sources", "my version of the mini-mental status exam"). In sum, there was remarkable divergence between clinician's actual and optimal risk assessment procedures, and little qualitative explanation of their actual procedures used. Clinicians appeared to rarely use, and to have little confidence in, standardized measures.

[Insert Table 2 about here]

\section{How often, and for how long, are risk assessments conducted?}

Clinicians were asked questions about the duration of risk assessment. First, they were asked about the average time demands for them to conduct a risk assessment. They reported that, on average, 13.33 minutes was 
spent assessing risk across the various domains. They also indicated that an optimal assessment should take nearly twice this time $($ mean $=23.99$ minutes) and that their clients generally could tolerate an assessment somewhere in between (mean $=18.09$ minutes). There was considerable variability in responses for each of these, with standard deviations approaching or exceeding each of these values (i.e., 15.00, 22.45 and 22.71 respectively). In sum, the actual time spent conducting risk assessment was far less than what would be spent conducting an optimal assessment, and there was considerable variability across clinicians.

Clinicians were next asked about the actual and optimal frequency of their risk assessments (Table 3). There was considerable variability across risk domains, nonetheless, several trends emerged. Overall, the frequencies of actual and optimal risk assessments were fairly similar. Averaged across risk domains, optimal frequency of at least once per day was endorsed by $59 \%$ of clinicians, which was very close to the $57 \%$ reported for actual frequency. Across individual domains however, there were disparities between optimal and actual frequencies reported. The largest discrepancy was observed for self-harm, with $73 \%$ of clinicians indicating assessments should occur at least daily, whereas only $56 \%$ of clinicians indicating that daily assessments were actually conducted. Importantly, approximately $18 \%$ of clinicians reported actually assessing risk in intervals greater than a month, though only $5 \%$ of clinicians reported that this was optimal.

[Insert Table 3 about here]

Comparing responses as a function of inpatient versus outpatient treatment settings, there were some important similarities. In terms of the optimal frequency of self and other-harm assessment, approximately three quarters of clinicians from both settings indicated at least daily assessment was ideal. For other types of risk, the results varied between settings. Approximately two-thirds or more of clinicians from inpatient/Intensive OutPatient (IOP) settings recommended at least daily assessment for psychosis, medication side effects, and treatment noncompliance which was much higher than reported in the outpatient setting (differences of $14 \%, 36 \%$, and $31 \%$ respectively). With respect to frequency of assessment, there was at least a $20 \%$ discrepancy in daily assessments between inpatient/IOP and outpatient settings for self-harm (67\% versus $44 \%$ respectively), decompensation (65\% versus $45 \%$ respectively), medication side effect ( $71 \%$ versus $25 \%$ respectively), and treatment noncompliance (64\% versus $35 \%$ respectively). Hence, daily assessment was recommended and practiced by most clinicians for the 
inpatient/IOP setting. Daily assessment of self-harm was recommended by most clinicians for the outpatient setting as well, though this was far below what was actually practiced.

\section{How can risk assessment be improved, and what role can technology play in this?}

Clinicians were next asked how risk assessment can be improved. First, they provided Likert-style responses to a list of potential concerns using a scale from 1 (not at all concern) to 5 (extreme concern). These concerns covered a range of items related to accuracy, resources needed to conduct the assessment and share the results, and practical issues involving accessing and sharing results. The results are included in Table 6. Overall, the average responses fell somewhere between 2.12 (a little) and 3.57 (somewhat to very much). The most notable concerns were expressed in response to accuracy of assessments and getting results more quickly. Fewer concerns involved being able to track patients and access their results remotely. Comparing clinicians from inpatient versus outpatient settings, there were two notable differences in ratings (i.e., .50 item difference): getting results more quickly (3.37 versus 2.75 respectively) and being able to access results remotely (2.87 versus 2.35 respectively).

\section{[Insert Table 4 about here]}

Clinicians next completed open-ended questions regarding concerns they had and how risk assessment could be improved. These question focused on risk assessment generally as opposed to specific types of risk assessment. The concerns were varied and centered around six themes. The most frequently noted concerns involved a lack of accuracy of risk assessment (noted by $23 \%$ of clinicians) and problems in alerting and sharing of critical risk assessment information (noted by $26 \%$ of clinicians). Other important themes involved inadequate time in session to conduct risk assessments (noted by $14 \%$ of clinicians), frequency of risk assessments (noted by $12 \%$ of clinicians), technical issues (e.g., slow computers/medical record access; noted by $9 \%$ of clinicians), and lack of uniformity between clinicians at the same organization (shared by $9 \%$ of clinicians). Of the responses, only one specifically mentioned the use of technology or methodologies to improve accuracy and efficiency. When asked about new tools or procedures for tracking risk status that might be helpful for patients and staff, $67 \%$ directly responded that they were not aware of any solutions, and an additional $27 \%$ failed to meaningfully include any mention of technology or innovation in their response. Technology-based solutions were present in only $14 \%$ of 
responses. Strikingly, in no response was there mention of biobehavioral monitoring or objective assessment of any kind.

\section{Conclusions}

Technological and methodological advances hold the potential to greatly improve the accuracy and efficiency of risk assessment for a variety of clinical events. However, it is unclear whether clinicians, a primary stakeholder, are aware of these potential advances. The present study evaluated current and future risk assessment practices in a multi-disciplinary sample of clinicians recruited from diverse settings. As in prior studies, risk assessment was judged to be an important part of practice involving patients with a broad range of SMIs. There was considerable variability in how clinicians conducted risk assessment, and few of the clinicians explicated their assessment procedures beyond tying it to a broader mental status examination or interview. In fact, few clinicians endorsed using standardized risk assessment instruments, and many reported low confidence in their clinical utility. That being said, clinicians were not using the risk assessment procedures that they reportedly were most confident in. The reasons for this are unclear, but may reflect time demands, as clinicians reported spending approximately half the time conducting individual risk assessments that would be needed for optimal assessments. Importantly, it seems unlikely that increased time would dramatically improve risk prediction accuracy, except perhaps indirectly through improved rapport, increased information, reduced clinician stress and burden and improved documentation. When asked about improving risk assessment, virtually no clinicians acknowledged biobehavioral or objective technologies, pattern recognition, or ambulatory recording. A few mentioned potentially using technology to help connect clinicians and improve communication, though clinicians largely seemed to be unaware or perhaps pessimistic about the potential for risk assessment to improve.

The present findings should be evaluated in light of several limitations. First, our sample was not necessarily representative of most clinicians in the world. Second, aspects of this survey were qualitative in nature. While potentially providing rich responses, characterizing null findings are particularly challenging. Nonetheless, there are important implications for the future. Despite considerable attention in academic, private-sector and even governmental agencies, clinicians in the present sample seemed to be generally unaware or unconvinced that technology can play a significant role in improving the practice of risk assessment. Advances to risk assessment systems, by incorporating pattern recognition analytic techniques, electronic medical records, and alert systems has 
been developed and, to varying degrees, adopted and implemented by large agencies (Hoffmire et al., 2016; Kessler et al., 2013; Schoenbaum et al., 2014), and similar algorithms are being developed for other types of risk (Cannon et al., 2008b, 2016). Despite these sorts of advances, major stakeholders appear to be largely unaware of these efforts. This presents an obvious problem in terms of implementation, as translating technological and methodological advances into clinical practice will require the attention and participation of clinicians. Increased outreach to and involvement from clinicians is most certainly warranted given that these assessments are primarily being developed to serve them and the patients under their care. 


\section{References}

Beal, A. C. (2012). The Patient-Centered Outcomes Research Institute (PCORI) National Priorities for Research and Initial Research Agenda. Jama, 307(15), 1583. https://doi.org/10.1001/jama.2012.500

Ben-Zeev, D., Davis, K. E., Kaiser, S., Krzsos, I., \& Drake, R. E. (2013). Mobile technologies among people with serious mental illness: Opportunities for future services. Administration and Policy in Mental Health and Mental Health Services Research, 40(4), 340-343. https://doi.org/10.1007/s10488-012-0424-X

Ben-Zeev, D., Drake, R. E., Corrigan, P. W., Rotondi, A. J., Nilsen, W., \& Depp, C. (2012). Using contemporary technologies in the assessment and treatment of serious mental illness. American Journal of Psychiatric Rehabilitation, 15(4), 357-376. https://doi.org/10.1080/15487768.2012.733295

Bernert, R. A., Hom, M. A., \& Roberts, L. W. (2014). A review of multidisciplinary clinical practice guidelines in suicide prevention: Toward an emerging standard in suicide risk assessment and management, training and practice. Academic Psychiatry, 38(5), 585-592. https://doi.org/10.1007/s40596-014-0180-1

Boudreaux, E. D., \& Horowitz, L. M. (2014). Suicide risk screening and assessment: Designing instruments with dissemination in mind. American Journal of Preventive Medicine, 47(3 SUPPL. 2), S163-S169. https://doi.org/10.1016/j.amepre.2014.06.005

Bridge, J. A., Horowitz, L. M., \& Campo, J. V. (2017). ED-SAFE-can suicide risk screening and brief intervention initiated in the emergency department save lives? JAMA Psychiatry, 74(6), 555-556. https://doi.org/10.1001/jamapsychiatry.2017.0677

Brodsky, S. L. (1988). Fear of Litigation in Mental Health Professionals. Criminal Justice and Behavior, 15(4), 492-500. https://doi.org/10.1177/0093854888015004006

Campbell, M. A., French, S., \& Gendreau, P. (2009). The prediction of violence in adult offenders: A meta-analytic comparison of instruments and methods of assessment. Criminal Justice and Behavior, 36(6), 567-590. https://doi.org/10.1177/0093854809333610

Cannon, T. D., Cadenhead, K., Cornblatt, B., Woods, S. W., Addington, J., Walker, E., ... Heinssen, R. (2008a). Prediction of psychosis in youth at high clinical risk: A multisite longitudinal study in North America. Archives of General Psychiatry, 65(1), 28-37. https://doi.org/10.1001/archgenpsychiatry.2007.3

Cannon, T. D., Cadenhead, K., Cornblatt, B., Woods, S. W., Addington, J., Walker, E., ... Heinssen, R. (2008b). Prediction of psychosis in youth at high clinical risk: A multisite longitudinal study in North America. 
Running head: CLINICIAN PERSPECTIVE ON RISK ASSESSMENT

Archives of General Psychiatry, 65(1), 28-37. https://doi.org/10.1001/archgenpsychiatry.2007.3

Cannon, T. D., Yu, C., Addington, J., Bearden, C. E., Cadenhead, K. S., Cornblatt, B. A., .. Kattan, M. W. (2016). An individualized risk calculator for research in prodromal psychosis. American Journal of Psychiatry, 173(10), 980-988. https://doi.org/10.1176/appi.ajp.2016.15070890

Carrión, R. E., Cornblatt, B. A., Burton, C. Z., Tso, I. F., Auther, A. M., Adelsheim, S., .. McFarlane, W. R. (2016). Personalized prediction of psychosis: External validation of the NAPLS-2 psychosis risk calculator with the EDIPPP project. American Journal of Psychiatry, 173(10), 989-996. https://doi.org/10.1176/appi.ajp.2016.15121565

Chan, M. K. Y., Bhatti, H., Meader, N., Stockton, S., Evans, J., O’Connor, R. C., ... Kendall, T. (2016). Predicting suicide following self-harm: Systematic review of risk factors and risk scales. British Journal of Psychiatry, 209(4), 277-283. https://doi.org/10.1192/bjp.bp.115.170050

Chan, S., Torous, J., Hinton, L., \& Yellowlees, P. (2015). Towards a Framework for Evaluating Mobile Mental Health Apps. Telemedicine and E-Health, 21(12), 1038-1041. https://doi.org/10.1089/tmj.2015.0002

Cohen, A. S., \& Elvevåg, B. (2014). Automated computerized analysis of speech in psychiatric disorders. Current Opinion in Psychiatry, 27(3), 203-209. https://doi.org/10.1097/YCO.0000000000000056

Cohen, A. S. (2019). Advancing ambulatory biobehavioral technologies beyond "proof of concept": Introduction to the special section. Psychological assessment, 31(3), 277.

Gaynes, B. N., West, S. L., Ford, C. A., Frame, P., Klein, J., \& Lohr, K. N. (2004). Screening for Suicide Risk in Adults: A Summary of the Evidence for the U.S. Preventive Services Task Force. Annals of Internal Medicine, 140(10), 822-835+I. https://doi.org/10.7326/0003-4819-140-10-200405180-00023

Grove, W. M., Zald, D. H., Lebow, B. S., Snitz, B. E., Nelson, C., Snitz, B. E., \& Grove, M. (2000). Clinical Versus Mechanical Prediction : A Meta - Analysis. Hedges \& Olkin, 12(1), 19-30. https://doi.org/10.1037/10403590.12.1.19

Hafeman, D. M., Merranko, J., Goldstein, T. R., Axelson, D., Goldstein, B. I., Monk, K., ... Birmaher, B. (2017). Assessment of a person-level risk calculator to predict new-onset bipolar spectrum disorder in youth at familial risk. JAMA Psychiatry, 74(8), 841-847. https://doi.org/10.1001/jamapsychiatry.2017.1763

Harrison, S. L., de Craen, A. J. M., Kerse, N., Teh, R., Granic, A., Davies, K., ... Stephan, B. C. M. (2017). Predicting Risk of Cognitive Decline in Very Old Adults Using Three Models: The Framingham Stroke Risk 
Running head: CLINICIAN PERSPECTIVE ON RISK ASSESSMENT

Profile; the Cardiovascular Risk Factors, Aging, and Dementia Model; and Oxi-Inflammatory Biomarkers. Journal of the American Geriatrics Society, 65(2), 381-389. https://doi.org/10.1111/jgs.14532

Heeringa, S. G., Gebler, N., Colpe, L. J., Fullerton, C. S., Hwang, I., Kessler, R. C., ... Ursano, R. J. (2013). Field procedures in the Army Study to Assess Risk and Resilience in Servicemembers (Army STARRS). International Journal of Methods in Psychiatric Research, 22(4), 276-287. https://doi.org/10.1002/mpr.1400

Hoffmire, C., Stephens, B., Morley, S., Thompson, C., Kemp, J., \& Bossarte, R. M. (2016a). VA suicide prevention applications network: A national health care system-based suicide event tracking system. Public Health Reports, 131(6), 816-821. https://doi.org/10.1177/0033354916670133

Hoffmire, C., Stephens, B., Morley, S., Thompson, C., Kemp, J., \& Bossarte, R. M. (2016b). VA suicide prevention applications network: A national health care system-based suicide event tracking system. Public Health Reports, 131(6), 816-821. https://doi.org/10.1177/0033354916670133

Holmlund, T. B., Foltz, P. W., Cohen, A. S., Johansen, H. D., Sigurdsen, R., Fugelli, P., ... \& Elvevåg, B. (2019). Moving psychological assessment out of the controlled laboratory setting: Practical challenges. Psychological assessment, 31(3), 292.

Insel, T. R. (2008). Assessing the economic costs of serious mental illness. American Journal of Psychiatry, 165(6), 663-665. https://doi.org/10.1176/appi.ajp.2008.08030366

Insel, T. R. (2009). Translating scientific opportunity into public health impact: A strategic plan for research on mental illness. Archives of General Psychiatry, 66(2), 128-133. https://doi.org/10.1001/archgenpsychiatry.2008.540

Joseph, J., Kremen, W. S., Franz, C. E., Glatt, S. J., van de Leemput, J., Chandler, S. D., ... Twamley, E. W. (2017). Predictors of current functioning and functional decline in schizophrenia. Schizophrenia Research, 188, 158164. https://doi.org/10.1016/j.schres.2017.01.038

Kennedy, M., \& Gill, M. (1997). Patient litigation following a homicide - implications for the assessment and managment of risk. Int Review Psychiatr, 9(2-3), 179-186. https://doi.org/abs/10.1080/09540269775376

Kessler, R. C., Aguilar-Gaxiola, S., Alonso, J., Chatterji, S., Lee, S., Ormel, J., ... Wang, P. S. (2009). The global burden of mental disorders: An update from the WHO World Mental Health (WMH) surveys. Epidemiologia E Psichiatria Sociale, 18(1), 23-33. https://doi.org/10.1017/S1121189X00001421

Kessler, R., \& Glasgow, R. E. (2011). A proposal to speed translation of healthcare research into practice: Dramatic 
change is needed. American Journal of Preventive Medicine, 40(6), 637-644. https://doi.org/10.1016/j.amepre.2011.02.023

Kessler, R. C., Warner, C. H., Ivany, C., Petukhova, M. V., Rose, S., Bromet, E. J., ... Ursano, R. J. (2015). Predicting suicides after psychiatric hospitalization in US army soldiers: The Army Study to Assess Risk and Resilience in Servicemembers (Army STARRS). JAMA Psychiatry, 72(1), 49-57. https://doi.org/10.1001/jamapsychiatry.2014.1754

Large, M., Kaneson, M., Myles, N., Myles, H., Gunaratne, P., \& Ryan, C. (2016). Meta-analysis of longitudinal cohort studies of suicide risk assessment among psychiatric patients: Heterogeneity in results and lack of improvement over time. PLoS ONE, 11(6), e0156322. https://doi.org/10.1371/journal.pone.0156322

Nelson, B., McGorry, P. D., Wichers, M., Wigman, J. T. W., \& Hartmann, J. A. (2017). Moving from static to dynamic models of the onset of mental disorder a review. JAMA Psychiatry, 74(5), 528-534. https://doi.org/10.1001/jamapsychiatry.2017.0001

Nelson, H. D., Denneson, L. M., Low, A. R., Bauer, B. W., O?Neil, M., Kansagara, D., \& Teo, A. R. (2017). Suicide Risk Assessment and Prevention: A Systematic Review Focusing on Veterans. Psychiatric Services, 68(10), 1003-1015. https://doi.org/10.1176/appi.ps.201600384

O’Hagan, M., Cornelius, V., Young, A. H., \& Taylor, D. (2017). Predictors of rehospitalization in a naturalistic cohort of patients with bipolar affective disorder. International Clinical Psychopharmacology, 32(3), 115120. https://doi.org/10.1097/YIC.0000000000000163

Passmore, K., \& Leung, W. C. (2002). Defensive practice among psychiatrists: A questionnaire survey. Postgraduate Medical Journal, 78(925), 671-673. https://doi.org/10.1136/pmj.78.925.671

Peek, C. J., Glasgow, R. E., Stange, K. C., Klesges, L. M., Peyton Purcell, E., \& Kessler, R. S. (2014). The 5 r's: An emerging bold standard for conducting relevant research in a changing world. Annals of Family Medicine, 12(5), 447-455. https://doi.org/10.1370/afm.1688

Pestian, J. P., Sorter, M., Connolly, B., Bretonnel Cohen, K., McCullumsmith, C., Gee, J. T., ... Murphy, C. (2017). A Machine Learning Approach to Identifying the Thought Markers of Suicidal Subjects: A Prospective Multicenter Trial. Suicide and Life-Threatening Behavior, 47(1), 112-121. https://doi.org/10.1111/sltb.12312 Rothwell, P. M. (2005). External validity of randomised controlled trials: "to whom do the results of this trial apply?” Lancet, 365(9453), 82-93. https://doi.org/10.1016/S0140-6736(04)17670-8 
Rubin, A., Dolev, T., \& Zilcha-Mano, S. (2016). Patient demographics and psychological functioning as predictors of unilateral termination of psychodynamic therapy. Psychotherapy Research, 1-13. https://doi.org/10.1080/10503307.2016.1241910

Schmidt, A., Cappucciati, M., Radua, J., Rutigliano, G., Rocchetti, M., Dell'Osso, L., ... Fusar-Poli, P. (2017). Improving Prognostic Accuracy in Subjects at Clinical High Risk for Psychosis: Systematic Review of Predictive Models and Meta-analytical Sequential Testing Simulation. Schizophrenia Bulletin, 43(2), 375388. https://doi.org/10.1093/schbul/sbw098

Schoenbaum, M., Kessler, R. C., Gilman, S. E., Colpe, L. J., Heeringa, S. G., Stein, M. B., ... Cox, K. L. (2014a). Predictors of suicide and accident death in the army study to assess risk and resilience in servicemembers (army starrs) results from the army study to assess risk and resilience in servicemembers (army starrs). JAMA Psychiatry, 71(5), 493-503. https://doi.org/10.1001/jamapsychiatry.2013.4417

Schoenbaum, M., Kessler, R. C., Gilman, S. E., Colpe, L. J., Heeringa, S. G., Stein, M. B., ... Cox, K. L. (2014b). Predictors of suicide and accident death in the army study to assess risk and resilience in servicemembers (army starrs) results from the army study to assess risk and resilience in servicemembers (army starrs). JAMA Psychiatry, 71(5), 493-503. https://doi.org/10.1001/jamapsychiatry.2013.4417

Seidman, L. J., Shapiro, D. I., Stone, W. S., Woodberry, K. A., Ronzio, A., Cornblatt, B. A., ... Woods, S. W. (2016). Association of neurocognition with transition to psychosis: Baseline functioning in the second phase of the north American prodrome longitudinal study. JAMA Psychiatry, 73(12), 1239-1248. https://doi.org/10.1001/jamapsychiatry.2016.2479

Stuart, M. E., \& Weinrich, M. (1998). Beyond managing Medicaid costs: restructuring care. The Milbank Quarterly, 76(2), 251-80. Retrieved from http://www.ncbi.nlm.nih.gov/pubmed/9614422

Torous, J., \& Baker, J. T. (2016). Why psychiatry needs data science and data science needs psychiatry connecting with technology. JAMA Psychiatry, 73(1), 3-4. https://doi.org/10.1001/jamapsychiatry.2015.2622

Vassos, E., Di Forti, M., Coleman, J., Iyegbe, C., Prata, D., Euesden, J., ... Breen, G. (2017). An Examination of Polygenic Score Risk Prediction in Individuals With First-Episode Psychosis. Biological Psychiatry, 81(6), 470-477. https://doi.org/10.1016/j.biopsych.2016.06.028

Velligan, D. I., Weiden, P. J., Sajatovic, M., Scott, J., Carpenter, D., Ross, R., ... Expert Consensus Panel on Adherence Problems in Serious and Persistent Mental Illness. (2009). The expert consensus guideline series: 
Adherence problems in patients with serious and persistent mental illness. The Journal of Clinical Psychiatry, 70 Suppl 4(Suppl. 4), 1-46. https://doi.org/http://dx.doi.org/10.4088/JCP.7090su1cj

Vitacco, M. J., Tabernik, H. E., Zavodny, D., Bailey, K., \& Waggoner, C. (2016). Projecting Risk: The Importance of the HCR-20 Risk Management Scale in Predicting Outcomes with Forensic Patients. Behavioral Sciences \& the Law, 34(2-3), 308-320. https://doi.org/10.1002/bsl.2221

Walsh, C. G., Ribeiro, J. D., \& Franklin, J. C. (2017). Predicting Risk of Suicide Attempts Over Time Through Machine Learning. Clinical Psychological Science, 5(3), 457-469. https://doi.org/10.1177/2167702617691560

Wand, T. (2012). Investigating the evidence for the effectiveness of risk assessment in mental health care. Issues in Mental Health Nursing, 33(1), 2-7. https://doi.org/10.3109/01612840.2011.616984

Wilbert, J. R., \& Fulero, S. M. (1988). Impact of Malpractice Litigation on Professional Psychology: Survey of Practitioners. Professional Psychology: Research and Practice, 19(4), 379-382. https://doi.org/10.1037/07357028.19.4.379

Wu, E. Q., Birnbaum, H. G., Shi, L., Ball, D. E., Kessler, R. C., Moulis, M., \& Aggarwal, J. (2005). The economic burden of schizophrenia in the United States in 2002. Journal of Clinical Psychiatry, 66(9), 1122-1129. https://doi.org/10.4088/JCP.v66n0906

Yang, M., Wong, S. C. P., \& Coid, J. (2010). The efficacy of violence prediction: A meta-analytic comparison of nine risk assessment tools. Psychological Bulletin, 136(5), 740-767. https://doi.org/10.1037/a0020473 
Table 1. Descriptive data for service professionals $(n=70)$

\begin{tabular}{|c|c|}
\hline Primary Employment setting $^{\mathbf{1}}$ & $\%$ \\
\hline Emergency Room & 17 \\
\hline Inpatient Treatment Facility & 41 \\
\hline Intensive Outpatient Facility & 6 \\
\hline Forensic Facility & 3 \\
\hline Outpatient Clinic & 45 \\
\hline Other & 19 \\
\hline \multicolumn{2}{|l|}{ Primary Training $^{\mathbf{1}}$} \\
\hline Medicine & 22 \\
\hline Psychology & 19 \\
\hline Social Work & 16 \\
\hline Counseling & 17 \\
\hline Nursing & 17 \\
\hline Other & 9 \\
\hline
\end{tabular}

1. Response options were mutually exclusive (i.e., only one response per participant) 
Table 2. Format of risk assessments conducted by clinicians: primary format used versus the format engendering greatest confidence.

\begin{tabular}{|c|c|c|c|c|c|c|}
\hline & & $\begin{array}{c}\text { Formal Mental } \\
\text { Status Exam }\end{array}$ & $\begin{array}{c}\text { Informal Mental } \\
\text { Status Exam }\end{array}$ & $\begin{array}{c}\text { Structured } \\
\text { Clinical } \\
\text { Interview }\end{array}$ & $\begin{array}{c}\text { Unstructured } \\
\text { Clinical } \\
\text { Interview }\end{array}$ & $\begin{array}{c}\text { Standardized } \\
\text { Clinical } \\
\text { Measure }\end{array}$ \\
\hline \multirow[t]{2}{*}{ Risk of harming self } & Primary Format Used ${ }^{1}$ & $29 \%$ & $30 \%$ & $25 \%$ & $13 \%$ & $3 \%$ \\
\hline & Greatest Confidence $^{1}$ & $23 \%$ & $8 \%$ & $35 \%$ & $31 \%$ & $4 \%$ \\
\hline \multirow[t]{2}{*}{ Risk of harming others } & Primary Format Used ${ }^{1}$ & $29 \%$ & $30 \%$ & $26 \%$ & $12 \%$ & $3 \%$ \\
\hline & Greatest Confidence $^{1}$ & $23 \%$ & $8 \%$ & $33 \%$ & $33 \%$ & $5 \%$ \\
\hline \multirow[t]{2}{*}{ Psychosis } & Primary Format Used ${ }^{1}$ & $30 \%$ & $33 \%$ & $26 \%$ & $9 \%$ & $1 \%$ \\
\hline & Greatest Confidence $^{1}$ & $20 \%$ & $13 \%$ & $35 \%$ & $26 \%$ & $4 \%$ \\
\hline \multirow[t]{2}{*}{ Functional Decompensation } & Primary Format Used ${ }^{\mathbf{1}}$ & $30 \%$ & $27 \%$ & $27 \%$ & $6 \%$ & $5 \%$ \\
\hline & Greatest Confidence $^{1}$ & $15 \%$ & $8 \%$ & $40 \%$ & $28 \%$ & $3 \%$ \\
\hline \multirow[t]{2}{*}{ Medication side effects } & Primary Format Used ${ }^{1}$ & $23 \%$ & $28 \%$ & $28 \%$ & $13 \%$ & $8 \%$ \\
\hline & Greatest Confidence $^{1}$ & $11 \%$ & $15 \%$ & $41 \%$ & $26 \%$ & $7 \%$ \\
\hline \multirow[t]{2}{*}{ Treatment noncompliance } & Primary Format Used ${ }^{1}$ & $19 \%$ & $30 \%$ & $31 \%$ & $5 \%$ & $8 \%$ \\
\hline & Greatest Confidence $^{1}$ & $10 \%$ & $10 \%$ & $35 \%$ & $31 \%$ & $2 \%$ \\
\hline \multirow[t]{2}{*}{ Litigation } & Primary Format Used ${ }^{1}$ & $14 \%$ & $29 \%$ & $33 \%$ & $14 \%$ & $5 \%$ \\
\hline & Greatest Confidence $^{1}$ & $22 \%$ & $11 \%$ & $0 \%$ & $56 \%$ & $0 \%$ \\
\hline
\end{tabular}

${ }^{1 \cdot}$ Response options were mutually exclusive (i.e., only one response per participant) 
Table 3. Optimal versus actual frequency of risk assessments.

\begin{tabular}{|c|c|c|c|c|c|c|c|}
\hline & & $\begin{array}{c}\text { Multiple } \\
\text { times per } \\
\text { day }\end{array}$ & Daily & $\begin{array}{c}\text { Multiple } \\
\text { times per } \\
\text { week }\end{array}$ & Weekly & $\begin{array}{c}\text { Multiple } \\
\text { times month }\end{array}$ & Monthly \\
\hline \multirow[t]{2}{*}{ Risk of harming self } & Optimal assessment frequency $^{1}$ & $45 \%$ & $28 \%$ & $5 \%$ & $10 \%$ & $9 \%$ & $2 \%$ \\
\hline & Actual assessment frequency ${ }^{1}$ & $28 \%$ & $28 \%$ & $2 \%$ & $19 \%$ & $7 \%$ & $5 \%$ \\
\hline \multirow[t]{2}{*}{ Risk of harming others } & Optimal assessment frequency $^{1}$ & $53 \%$ & $23 \%$ & $8 \%$ & $5 \%$ & $5 \%$ & $5 \%$ \\
\hline & Actual assessment frequency ${ }^{1}$ & $41 \%$ & $31 \%$ & $3 \%$ & $10 \%$ & $3 \%$ & $0 \%$ \\
\hline \multirow[t]{2}{*}{ Psychosis } & Optimal assessment frequency $^{1}$ & $29 \%$ & $31 \%$ & $6 \%$ & $13 \%$ & $10 \%$ & $8 \%$ \\
\hline & Actual assessment frequency ${ }^{1}$ & $28 \%$ & $32 \%$ & $4 \%$ & $9 \%$ & $4 \%$ & $11 \%$ \\
\hline \multirow[t]{2}{*}{ Functional Decompensation } & Optimal assessment frequency $^{1}$ & $17 \%$ & $32 \%$ & $10 \%$ & $12 \%$ & $15 \%$ & $7 \%$ \\
\hline & Actual assessment frequency ${ }^{1}$ & $20 \%$ & $35 \%$ & $5 \%$ & $8 \%$ & $8 \%$ & $5 \%$ \\
\hline \multirow[t]{2}{*}{ Medication side effects } & Optimal assessment frequency $^{1}$ & $19 \%$ & $32 \%$ & $0 \%$ & $19 \%$ & $13 \%$ & $3 \%$ \\
\hline & Actual assessment frequency ${ }^{1}$ & $23 \%$ & $23 \%$ & $0 \%$ & $17 \%$ & $7 \%$ & $7 \%$ \\
\hline \multirow[t]{2}{*}{ Treatment noncompliance } & Optimal assessment frequency $^{1}$ & $20 \%$ & $24 \%$ & $6 \%$ & $22 \%$ & $6 \%$ & $16 \%$ \\
\hline & Actual assessment frequency ${ }^{1}$ & $21 \%$ & $29 \%$ & $4 \%$ & $19 \%$ & $4 \%$ & $4 \%$ \\
\hline \multirow[t]{2}{*}{ Litigation } & Optimal assessment frequency $^{1}$ & $0 \%$ & $0 \%$ & $0 \%$ & $0 \%$ & $0 \%$ & $0 \%$ \\
\hline & Actual assessment frequency ${ }^{1}$ & $0 \%$ & $22 \%$ & $11 \%$ & $22 \%$ & $0 \%$ & $22 \%$ \\
\hline
\end{tabular}

${ }^{1}$ Response options were mutually exclusive (i.e., only one response per participant) 
Table 4. Concerns regarding risk assessment, and how it can be improved?

\begin{tabular}{llc}
\hline & Mean & $\begin{array}{c}\text { Standard } \\
\text { Deviation }\end{array}$ \\
\hline Decreasing the amount of time it takes for an assessment & 2.40 & 1.29 \\
\hline Tracking (e.g., assessing) patients while not at your clinic (i.e., remotely) & 2.12 & 1.21 \\
\hline Liability issues (e.g., malpractice) & 2.78 & 1.06 \\
\hline Improving the accuracy of the assessments & 3.57 & 1.06 \\
\hline Getting results of the assessments more quickly & 3.12 & 1.05 \\
\hline Being able to access the results of an assessment remotely & 2.66 & 1.38 \\
\hline Increasing the frequency of assessments & 2.42 & 1.17 \\
\hline
\end{tabular}

Range 1 (not at all), 2 (a little), 3 (somewhat), 4(very much), and 5 (Extremely). 